\title{
A rare case of stricture urethra presenting as pyocele and urethrotunica vaginalis fistula
}

\author{
Sachin Patil, Apul Goel, Vishwajeet Singh, Satya Narayan Sankhwar
}

Department of Urology, King George's Medical University, Lucknow, Uttar Pradesh, India

\section{Correspondence to} Dr Sachin Patil,

drsachin.uro@gmail.com

\section{DESCRIPTION}

A 52-year-old man, with a known case of catheterinduced stricture urethra, presented with swelling and pain in the right scrotum with a high-grade fever for 8 days following an attempt of urethral stricture dilation using metallic bougie for urinary retention. On examination, he was found to have right epididymo-orchitis with pyocele. He underwent suprapubic catheter (SPC) placement and incision and drainage of pyocele. Retrograde urethrogram (after stabilisation of general condition) showed distal bulbar urethral stricture $(1.5 \mathrm{~cm})$ with extravasation of contrast in the right scrotum inside tunica vaginalis (figure 1). Urethroscopy showed stricture at the distal bulbar urethra with fistulous opening on the right lateral wall of the urethra distal to stricture (figure 2). A guide wire passed through scrotal end of the fistula was seen coming through urethral end of the fistula and then through the external urinary meatus (figures 3-5). The patient was discharged in satisfactory general condition with a plan of definitive

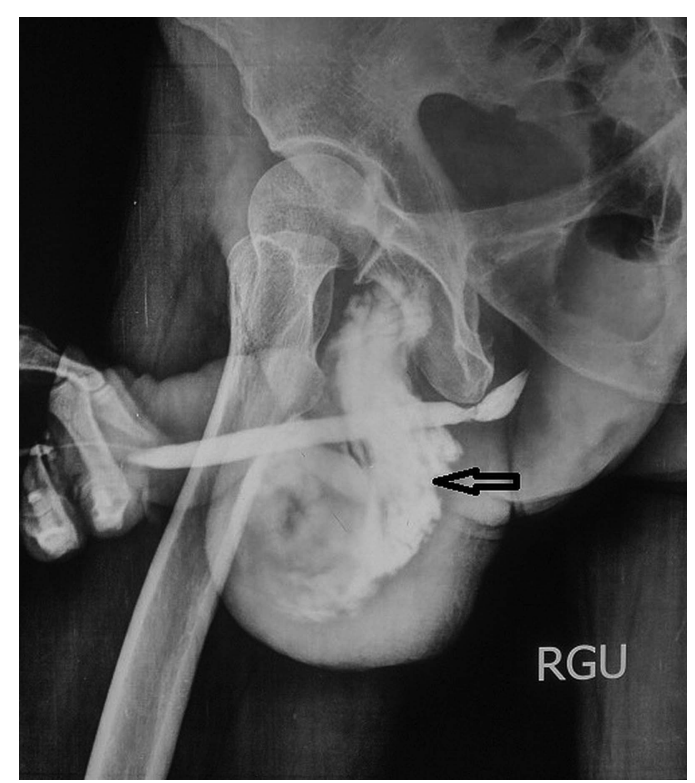

Figure 1 Retrograde urethrogram showing extravasation of contrast in the right scrotum inside tunica vaginalis (indicated by black arrow) with stricture in the distal bulbar urethra.

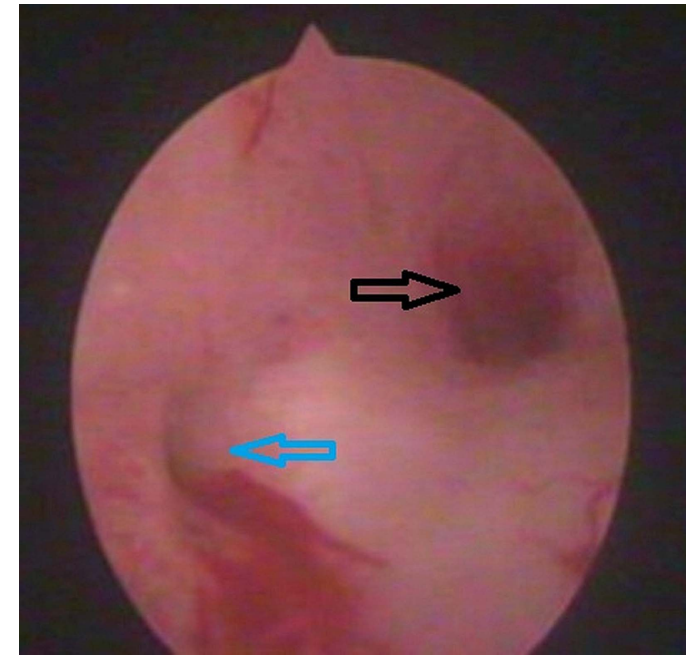

Figure 2 Urethroscopy showing stricture at the distal bulbar urethra (black arrow) with fistulous opening on the right lateral wall of urethra (blue arrow) distal to stricture.

management of stricture after resolution of the fistula.

Perineum, rectum and genital structures are sites of fistulous communications with urethra. The literature is limited to a few case reports of urethra-scrotal fistula. ${ }^{1}$ There is no report of fistulous communication between urethra and tunica vaginalis. Retrograde urethrography, voiding cystourethrography and cystourethroscopy are the main diagnostic modalities. ${ }^{3}$ Such patients are managed initially with temporary urinary diversion (SPC) followed by a definitive treatment of underlying causes if any.

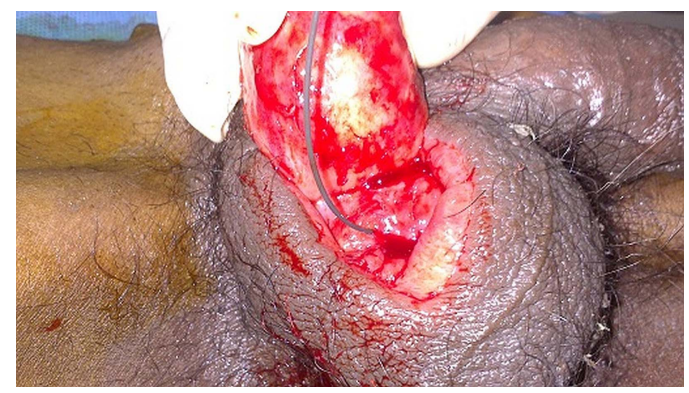

Figure 3 Guide wire passed through scrotal end of the fistula. 


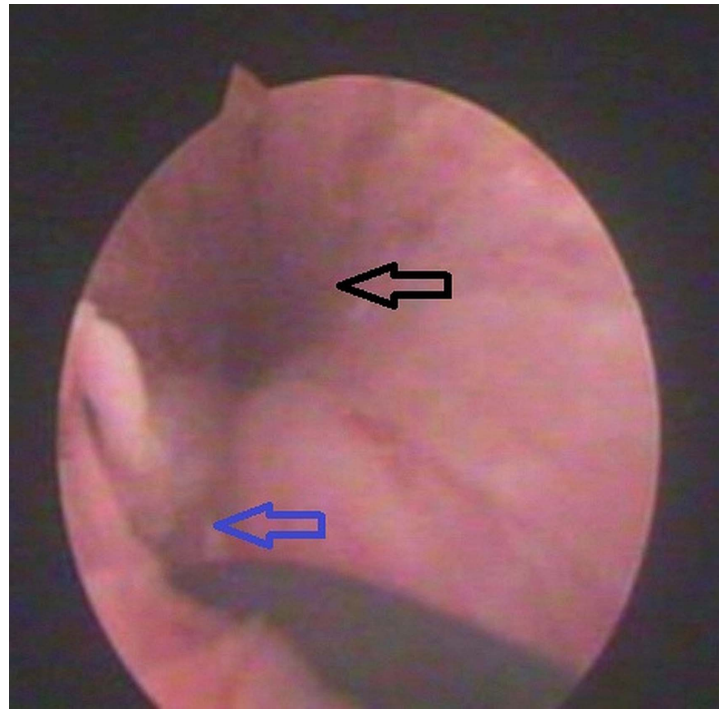

Figure 4 Guide wire passed through scrotal end of the fistula coming through urethral end (blue arrow)-urethroscopic view.

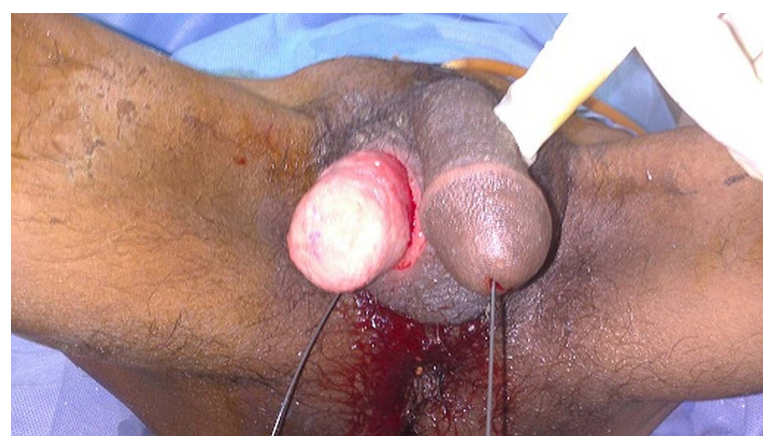

Figure 5 Guide wire passed through scrotal end of the fistula coming out through the external urinary meatus.

\section{Learning points}

- Fistulous communication of urethra to tunica vaginalis is a rare finding.

- Chances of such fistula are increased in the presence of urethral stricture because of forceful blind urethral dilation attempt. So, one has to be extremely careful while attempting urethral dilation in patients with a previous history of urethral stricture disease.

- Such patients are managed by initial suprapubic catheterisation followed by definitive management of stricture after complete resolution of the fistula.

Contributors All the authors have contributed to the conception, editing and final preparation of the manuscript.

\section{Competing interests None.}

Patient consent Obtained.

Provenance and peer review Not commissioned; externally peer reviewed.

\section{REFERENCES}

1 Bouchikhi AA, Amiroune D, Tazi MF, et al. Isolated urethral tuberculosis in a middle-aged man: a case report. J Med Case Rep 2013;7:97.

2 Bakhshi GD, Borisa AD, Shaikh AS, et al. Multiple scrotal fistulae -sequel of chronic giant urethral diverticular stone at penoscrotal junction. Bombay Hosp J 2011;53:261-3.

3 Jafri SZ, Roberts JL, Berger BD. Fistulas of the genitourinary tract. In: Pollack HM, McClennan BL. eds Clinical urography. Philadelphia, PA: Saunders, 2000:2992-3011.

Copyright 2014 BMJ Publishing Group. All rights reserved. For permission to reuse any of this content visit http://group.bmj.com/group/rights-licensing/permissions.

BMJ Case Report Fellows may re-use this article for personal use and teaching without any further permission.

Become a Fellow of BMJ Case Reports today and you can:

- Submit as many cases as you like

- Enjoy fast sympathetic peer review and rapid publication of accepted articles

- Access all the published articles

- Re-use any of the published material for personal use and teaching without further permission

For information on Institutional Fellowships contact consortiasales@bmjgroup.com

Visit casereports.bmj.com for more articles like this and to become a Fellow 